\title{
Research on Rhetoric Art of Japanese Waka
}

\author{
Yaling $\mathrm{Li}^{1}$ \\ ${ }^{1}$ College of Literature and Law, Sichuan Agricultural University, Ya'an, Sichuan, 625014
}

KEYWORDS: Japanese Waka; Rhetoric Art; Literature Content

\begin{abstract}
Japanese Waka is a language of the art forms with national characteristics. In the thousand years of the development process, in terms of form, rhyme and rhetoric, it formed its own unique artistic style. And songs in these art forms and techniques of decorating, become colorful art treasures. However, these art forms are difficult to use in place of his language and expression. This paper studies the Japanese Waka and rhetorical skills and will be helpful for the for the appreciation of Japan and its literature.
\end{abstract}

\section{Introduction}

Japanese Waka constituted by a 31 pseudonym, so called thirty word poetry. On the Japanese Waka school, usually this 31 pseudonym, namely 31 tones divided into five, five sound of the original sentence, the first two of seven tones, the first three to five tones, more than three collectively of the Alliance; 4, 5, 7 tones each sentence, collectively referred to as the second line. That is, Japanese Waka are alternating 5,7 tone of consecutive abnormal short fixed verse. Words and short, is the word because most Japanese words are made up of two or more composed tone, so a Japanese Waka, in addition to the role played grammar word and auxiliary verb, but with a meaningful up to 10 or so. For Japanese Waka authors, the use of so few words express rather complicated things or feelings really easy. Therefore, since the Japanese Waka stereotypes a lot of good songs in a symbol of constantly absorbing Chinese poetry, personification, pun, metaphor, dual basis parallelism and other rhetorical method, this also created a pillow word sequencer word edge language and other rhetorical skills, thus increasing the rhetorical effect, improve the artistic expression of language. Pillow word generally consists of five tones constituted as the basic fixed idiomatic phrase is derived directly or modified later for specific words, in order to achieve the increase in Lenovo, rich in content, tone adjustment and other rhetorical effect.

\section{Rhetoric Characteristics of Japanese Waka}

Classical syntax for rhetorical Japanese Waka and haiku verse and other works, in addition to Poetry and the same dual reference, outside anthropomorphic, and pillow word, word order, edge language, allusions quarter of language, punctuation and other unique rhetorical skills, through the application of a variety of changes to enhance the rhetorical sense of coherent and compact, forming a simple, subtle, a pale features [.

Pillow word is Japanese Waka rhetorical crown on top of certain words. Generally, it is composed of five syllables. Classical Grammar pillow in the form of word play some role intonation adjustment; in the content, add some words to the back of the symbolic colors, words and pillow behind is an adjunct is fixed. Pillow word usually appears in the first sentence of Japanese 
Waka or third sentence, and later gradually becomes mere decoration, has lost most of the original intent of the translation may not be translated.

Word order to elicit a word and preceded by a modifier, parables or other forms of homonyms repeatedly drawn back related words. Words and word order pillow on the same role, but generally not fixed by the seven syllables of the words above configuration, no specific associated words. Sequence between words and words like lead pillow word as fixed, and more creative, you can improvise is the author of creation. Therefore, the translation must be translated. Word sequence is modified by analogy significance level.

Pun is the use of words in unison (or almost sound) situation, so that a word concerning a rhetorical approach both sense. General expression of both natural scenery and people's emotions mean. After the Muromachi period, this rhetoric is also often used for the genre other than Japanese Waka (such as ballads, said the wording, net glass etc.). In translation, the translated pun meaning.

Yuan phrase refers to a Japanese Waka center with a word meaning (or expression) on the content closely related words. By Lenovo and other ways to make it more fun expression meaning, Yuan and Japanese Waka language general theme is not directly related. Yuan language is often used in conjunction with pun skill. Translation, generally translated pun meaning, but Yuan language may not be directly translated edge language.

Personification is to plants, animals and inanimate, abstract to describe the food as people is a rhetorical device, it can be said that a special kind of metaphor.

Allusions refers to the creation of Japanese Waka, the ancient name of the song in a certain song sentence blend naturally in your own Japanese Waka, a new meaning and a modified technique. In this case, generally referred to all Japanese Waka / 0 of the song, the re-creation of Japanese Waka called / Allusion this song take this rhetoric, after the Kamakura era became popular in the Middle Ages, edited the new ancient and modern Japanese Waka focus particularly prevalent.

End of statement, also known as body punctuation noun, refers to the end of the fifth Japanese Waka Sentences body section made by the end of the whole song, songs bring a finish to the whole of rhetoric. This rhetorical skills in a new era of ancient and modern is most prevalent.

Generalized Japanese Waka includes long song, ballad, song rotating head, foot stone Buddha song and so on. The earliest extant Japanese Waka Set 5 Manyoshu 6, the largest number of tanka, followed by a long song. 5 to 6 new set of ancient Japanese Waka, it is only a collection of tanka. Tanka of 31 tones, sub-section in the form of five, seven, five, seven, seven. Japanese Waka in five hundred seventy-two holiday punctuation, long and short in front, called fifty-seven tune. Namely: two pauses (two cut l) and four pauses (four cut l) is one of the first sentence, the contents of two Japanese Waka beginning constitute a relatively independent meaning a pause, third, four constitute a layer of meaning to do a pause, and finally to Qiyin knot sentence. Since the beginning of the phrase when two clauses are pentameter and Qiyin, so called fifty-seven tone which is characterized to have a deep, calm, dignified characteristics.

\section{Aesthetic Features of Japanese Waka}

Chinese poetry and poetic theory is incoming early Japan, the Chinese nation, "Poems" and Confucianism "people's livelihood" and sense of social responsibility once the influence of Japanese poetry, which is reflected in the early Japanese poetry theory. But the Japanese people understand the nature of poetry with the Han nationality varies greatly. "In the Japanese Waka almost no criticism of social customs, written in kana Story is also minimal. Only when writing in Chinese, the Japanese mainland literary talent to follow the habit of showing concern for the community. However, this kind of social concern, and the Tang Dynasty poet of social concern is different. "' in 
the Chinese classical literature, like $\mathrm{Du} \mathrm{Fu}$, as the political society and their own destiny linked, or anger, or typical lament of many poems, in the literary tradition in Japan of almost no. "' "leaves collection" songs almost without touching the political and social problems. in this sense, in general, and contemporary Tang in sharp contrast. "Japanese Waka's non-political, non-social tendencies is one of the distinctive characteristics of Japanese Waka Japanese, Japanese literature is also one of significant features.

Japan is a country of distinct season, seasonal changes bring the form and color of things change, natural form of this unsettled contributed to the Japanese people to change the nature of the sensitive and delicate psychology. French art historian Alley - Sherlock said: "The Japanese always have a strong sensibility and sensitivity." They always eyes on the side of natural things and scenes, everything is fleeting in nature, in all its forms and color are temporary presence, this impermanence and variable, giving them unforgettable impression. After the introduction of Buddhism to Japan, Buddhism "impermanence" and "Seji empty space that is the color" concept not only confirms but also greatly enhanced the "impermanence" consciousness. Japanese Waka demonstrated the impermanence of all things perishable individual life is the presence of personal experience, thus forming a "wind of aesthetics." This fellow letter said: "As a general way of thinking of the Japanese, they often put the United States as a very slim thing, as a kind of phenomenon will soon disappear." This is reflected in the concept of impermanence Zen Poetry. Japanese like to change in plant life forms to symbolize things "impermanence" concept. Japanese poetry or prose to the rich, colorful, delicate natural things personify beauty seasons, tells the heart of the fleeting nature of life sad feelings, thus forming a poetry singing seasons scene "season title" consciousness. There are no images of the four seasons of nature and even feel emotions, it will not create an awareness of the theme of season." Visible, poetry season title formed the feelings and stimulates the natural world.

From "Leaves Collection" era to modern times, Japanese Waka forms are short, one of the few long poem translated into Chinese only 50-60 sentences, visible, short form is one of the important characteristics of Japanese Waka. Leading to short Japanese Waka two reasons: First, from the Japanese Waka traditional look, focusing on Japanese Waka lyrical narrative is not too heavy, good lyrics often talk burst of emotional or psychological impression of the moment, not like the form of narrative poetry as lingering; aesthetics Second, Zen Buddhism deeply influenced the creative forms of Japanese Waka. Zen believes that everything that is animate death, life after death in the form of bulk, but also derived in the form of life on other things, all life forms are converted into each other, reincarnation and prosperous. Therefore, in all things in life, I have you, you have me, this constant transformation, derived endless "life chain" Zen is "one that is much more than that is a," "that is limited unlimited" concept thinking basis. The so-called Zen enlightenment, insight is in the subtle worlds, awareness "Seji empty space that is color" Buddha in natural things, "impermanence" in the "really" nature. The so-called Zen, is to show the way in artistic harmony between man and nature of life, the nature of impermanence and fleeting sentiment, and to comprehend the truth. Contemporary Japanese Zen master Suzuki said: "Zen really like us, facing the same universe and nature, but also, like us, the same object, the same special interest in the presence of deep frog jumped into the pool, snails sleep in banana leaves; butterflies. the flowers flying, leaving the moon shadows in the water; lily bloom between fields, autumn bursts, beat the cottage roof ...... for all this changes with the seasons and the natural scene, Chan Hing in every possible way. That is a much more namely a", "namely limited unlimited" concept art of Japan decided not to pursue the full, perfect, and tend to "failure of all", "rather critical" way to represent artists Zen Meaning of heart, has thus strengthened the Japanese Waka and simplified 
form of short features. We "Leaves Collection" of Japanese Waka haiku development process can be seen in the form of Japanese Waka increasingly short, refining trends clearly. Japanese haiku is a Japanese Waka shortest small one, as an independent body formed poetry in the 15th century. He was released from the body longer "even the song" in the "hair sentence" out.

\section{Conclusion}

Japanese classical Japanese Waka deeply rooted in nature, capturing tiny taste of life from the scene, to express the sentiment of life and love has been a characteristic of Japanese poetry survival. This is the source of Japanese classical poetry to flourish, but also the driving force of Japanese poetry going forward. Japanese classical Waka formally speaking, is short and streamlined, reflecting the Japanese small things special liking this feature. From the content, it can be funny in the light, the simple meaning in the apartment, fully embodies the subtle Japanese national character. Mastered classical Japanese Waka rhetorical trick is to appreciate Japanese classical Japanese Waka indispensable content. This paper focuses on common rhetorical techniques of classical Japanese Waka Japanese are introduced, in order to better appreciate the classical Japanese Waka Japanese, understand the meaning and expression of thought, to understand the Japanese aesthetic, outlook on life, values and views on love.

\section{Reference:}

[1] Valley Baoxiang, Jiang Miao. Japanese classical Japanese Waka rhetoric of [J]. Jilin Institute of Chemical Technology, 2010, 27 (6): 87-89.

[2] Jin Zhong. Translation form Japanese Waka and haiku - poetry combine the performance characteristics of different types [J]. People's Liberation Army International Studies University, 2011,34 (3): 78-80.

[3] plum fruit. Japanese Waka rhetorical skills and Translation of [J]. Japanese Study and Research, 1987, (4): 38-44.

[4] Li Ying. "The Tale of Genji" deconstruction Reading [J]. Lanzhou Jiaotong University, 2008,27 (5):80-82. 